\title{
LAS NIÑAS DEPOSITADAS. EL DESTINO DE LA MANO DE OBRA FEMENINA INFANTIL EN RÍO NEGRO A PRINCIPIOS DEL SIGLO XX' ${ }^{1}$
}

\author{
María E. ARGERI \\ IEHS-UNCPBA ${ }^{2}$ \\ Tandil, ARGENTINA
}

En este trabajo se analizan instantes fugaces en la vida de varias menores que estuvieron internadas en casas "decentes" y en conventos de monjas, a disposición del poder judicial, a principios del siglo XX, en el territorio nacional del Rio Negro (Norpatagonia). El depósito de menores, de larga tradición colonial es un tema olvidado por la historiografía argentina que analiza la problemática de construcción del poder y del estado republicanos.

"La historia es una pesadilla de la que quiero despertarme" Joyce.

\section{1}

Hace algunas décadas atrás, cuando los estados más poderosos se encontraban ocupados en la guerra de las galaxias, América Latina estaba inmersa en el proceso revolucionario, y desde Medellín comenzaba a difundirse la teología de la liberación, según los presupuestos del II Concilio Vaticano. En esa década, que fue también la del movimiento hip-

1 Una versión preliminar de este trabajo fue presentada en la II Reunión de Antropología del Mercosur, Piriápolis, 11-14 de noviembre de 1997.

2 Instituto de Estudios Históricos y Sociales "Profesor Juan Carlos Grosso", Universidad Nacional del Centro de la Provincia de Buenos Aires. 
pie y la revolución cultural china, yo cursaba la escuela primaria en un colegio de monjas, por decisión de mis padres. Por entonces, sólo sentía una terrible opresión que se expresaba en recurrente dolor de garganta y en rebeldía explícita, que me llevaba con mucha frecuencia a soportar penitencias en la dirección. No sabía que mi experiencia en ese colegio no distaba mucho de la que habían padecido otras niñas de mi edad en los lejanos años de principios de siglo -y esto por poner un límite temporal, siempre arbitrario-.

Tengo presente varias imágenes de esos años. Una de ellas es el recuerdo del mes de María. Hacia octubre o noviembre -la memoria borra los datos inconvenientes- debiamos llegar media hora antes. Formábamos fila y marchábamos en casta disciplina hacia la capiIla. Esta se encontraba recubierta de flores blancas, donadas por las familias más ricas o pretenciosas. Las puertas del recinto se encontraban siempre abiertas para evitar los frecuentes desmayos. El aroma del incienso se expandía por los claustros. El rito de la plegaria diaria comenzaba con una letanía seguida por un número preciso de avemarías. De esa jacultatoria sólo recuerdo los primeros versos, "Madre mia, amantísima, en todos los instantes de mi vida acuérdate de mí, miserable pecadora...", que los labios infantiles repetían sin comprender demasiado el significado de aquella sentencia.

En esa plegaria participábamos todas, las monjas, las maestras y las alumnas sin distinción de rango y condición. La diferenciación nunca se evidenciaba en los instantes de autoflagelación discursiva: sólo se mostraba en otros momentos. Por ejemplo, a la hora de recibir instrucción. Las alumnas regulares nos diferenciábamos en externas -condición que los hados me adjudicaron en suerte- y pupilas. Y las pupilas, entre las que abonaban la cuota de manutención y aquellas que, en realidad, eran internadas. Estas eran en su mayoría huérfanas o depositadas por los jueces de menores. Claro está que nosotras nada sabíamos de leyes ni de procesos judiciales. Pero sí algunas pocas, nos dábamos cuenta que las monjas disponían del tiempo de nuestras compañeras internadas.

En esos años de la escuela primaria, Filomena cursaba los primeros grados con nosotras. Tenía un rostro inexpresivo y, según decían, algunos años más que los correspondientes al nivel de su instrucción. Su vida era un misterio. Sólo podíamos observar su rostro surcado por arrugas demasiado prematuras, que hacían marco a una mirada más gastada que la de nuestras madres. Las maestras-monjas le decian burra, cuando se equivocaba en la resolución de algún problema. Filomena, mantenía también en esos casos una expresión indescifrable. La misma que le observábamos cada vez que venía, diariamente, la superiora o 
la monja responsable de la limpieza y la sacaban de clase para que fuera a limpiar las habitaciones, los baños y los patios. La escuela relucía, sin necesidad de lejía o cera. El brillo de los impecables pisos de mármol se conseguía con jabón común y la fuerza de los brazos de las internadas. La asepcia costaba demasiado poco a las arcas de las Hermanas de la Misericordia.

Filomena continuaba todavía en los grados primarios cuando nosotras nos despedíamos con un ihasta nunca! de los claustros, apretando fuertemente entre las manos el diploma de bachiller. Su imagen volvió a mi memoria cuando en el archivo de Río Negro comencé a leer varios expedientes referidos a menores depositadas, hacia principios del siglo, en las casas decentes o en los colegios de la orden salesiana de las Hermanas de María Auxiliadora. Un hilo común enlaza la historia de Filomena con la de aquellas otras jóvenes. Pero una aparente diferencia las separa, la vida de Filomena transcurría en los años de la teología de la liberación.

\section{2}

Serviliana y Angela M.; Rosa E.; Dorotea N.; Dominga L.; María H. y María A. ${ }^{3}$ vivieron en el Territorio Nacional del Río Negro, entre fines del siglo XIX y principios del siglo XX. Durante su minoría de edad compartieron un destino común con un sinnúmero de jóvenes de su misma condición social humilde, al quedar sometidas a las disposiciones de los poderes civil y religioso. Adscritas a la figura jurídica del depósito -práctica habitual cuyo fundamento legal data del derecho indiano, de larga tradición en el espacio hispanoamericano-4, bajo la excusa de regenerar los hábitos que habían aprehendido en sus respectivos núcleos familiares, su vida estuvo sujeta a un permanente traslado, cuyo destino era decidido por sacerdotes, jueces de menores, agentes policiales y tutores, quienes controlaban, de hecho, los circuitos de mano de obra forzada juvenil, constituyendo una oferta amplia que satisfizo tanto la demanda de trabajo sexual -para diferentes prostíbulos del país- como la doméstica -empleada en la esfera privada y en los conventos y colegios religiosos de mujeres-.

3 Los nombres corresponden a las personas reales, pero omitimos el apellido, abreviado en la inicial.

4 Para la educación de las niñas indias en el contexto colonial mexicano y la función que tuvo el depósito, cf. José María Kobayashi, La educación como conquista, México, El Colegio de México, 1985, Pilar Gonzalbo Aispuru, Historia de la educación en la época coIonial. El mundo indígena, México, El Colegio de México, 1990. 
Ahora bien, esta servidumbre femenina de nuevo cuño estuvo disimulada bajo los presupuestos modernizadores de las normas vigentes en el derecho y la moral pública de la sociedad republicana, y para los territorios nacionales signó uno de los aspectos centrales de la constitución del Estado Nación. En efecto, la guerra de ocupación que había finalizado de manera explícita en 1885 y que había dado por resultado el sometimiento de las poblaciones indias, trajo aparejada la construcción de un nuevo orden y con ello la imposición de una nueva legalidad, que trastocó todos los planos de la vida cotidiana. Las poblaciones indias remanentes y los nuevos migrantes -en su mayoría expulsados y marginados de los espacios modernizados por el capitalismo en Chile y Argentina-fueron sometidos al disciplinamiento de los cuerpos y las conciencias. Este proceso, que a la larga condujo a la transformación cultural, necesaria para el éxito de la proletarización de la mano de obra, se realizó mediante diferentes mecanismos: la pérdida del territorio; la prohibición de la boleada y de la caza; el uso de la papeleta de conchabo -que ya había caducado a nivel nacional-; y la acusación de vagancia, libertinaje, y atentados contra la moral pública.

Pero, el disciplinamiento estatal se caracterizó por la diferenciación sexual, en el momento de decidir la imputación, el procesamiento y la pena. Los varones fueron considerados sujetos vagos y peligrosos. Las mujeres, sospechadas por su sola condición femenina, fueron acusadas de libertinas y prostituidas, que debían ser sometidas a la tutela y dominio de los varones, o en su defecto controladas directamente por el Estado y la iglesia ${ }^{5}$. El Código Civil, las consideraba sujetos menores de derecho, al estipular la inferioridad juridica del género. Esta normativa fue la herramienta fundamental que dio base legal al disciplinamiento y a la desestructuración de los grupos domésticos, cuya reproducción biológica y cultural y cuya economía se estructuraban en torno al rancho ${ }^{6}$. La excusa fue, en todos los casos, la incapacidad de la mujer para detentar y ejercer la patria potestad sobre su prole. Con el cambio de normativa, luego de la guerra, todas las uniones maritales de hecho fueron consideradas ilegítimas y las madres perdieron atribuciones sobre sus hijos. La confluencia entre la norma jurídica y el presupuesto moral posibilitó el predominio estatal so-

5 En los territorios patagónicos, las mujeres y menores sospechados de delincuencia fueron puestos bajo la tutela de la Orden salesiana. Por decreto presidencial de octubre de 1894, los colegios y conventos de la orden funcionaban como cárceles, hasta que no se construyesen las cárceles estatales para mujeres.

6 Cf. María E. Argeri y Sandra Chía, "Bajo la lupa del poder. La vida cotidiana en los hogares boliches del Territorio Nacional del Río Negro, Norpatagonia, 1880-1930", Boletín Americanista, Barcelona, 1997. 
bre la vida cotidiana, los vínculos parentales y las relaciones íntimas. La exclusión de los varones, como sujetos estructurantes del grupo doméstico, se avaló en la inexistencia generalizada de uniones legitimadas y consagradas.

En este contexto, la desestructuración de los vínculos sociales y culturales se realizó a partir del desarrollo de la violencia institucional. Los menores de ambos sexos quedaron sujetos al arbitrio de las decisiones de los funcionarios y fueron, sin lugar a dudas, quienes pagaron el mayor costo social e individual de la transformación económica y política. La policía, los sacerdotes y la justicia repartían la mano de obra infantil y juvenil. Los menores fueron entregados como peones para los comercios y empresas rurales. Las menores tuvieron un destino más incierto, sometidas a la explotación económica y sexual. Las historias que relataremos -que constituyen instantes fugaces en la vida de las hermanas Serviliana y Angela M. (1908); Rosa E. (1889); Dorotea N. (1893), Dominga L. (1906); María H. (1910) y María A. (1892)- permitirán ilustrar algunos aspectos descuidados por la producción historiográfica argentina que analiza el proceso general de la conformación del Estado Nación.

\section{A}

Serviliana y Angela M. eran huérfanas y estaban bajo la tutoría del sacerdote Juan Aceto. En el invierno de 1908 tenían dieciséis y quince años respectivamente. Hacía casi siete meses, desde la Navidad del año anterior, que Aceto las había depositado en casa de la familia Rizzanelli, en la localidad de Choele Choel, departamento Avellaneda, del Territorio Nacional del Río Negro. La familia Rizzanelli estaba compuesta por Remigio, el tío de las menores -italiano, de cincuenta y cinco años, con treinta y cuatro años de residencia en el país, hacendado y dueño de una botica-, su esposa y los hijos de ambos, Saturnino de catorce años y Juan de quince años.

Serviliana y Angela fueron violadas. En el mes de junio de 1908, el sacerdote Aceto decide enviarlas a Bahía Blanca a un nuevo domicilio de depósito. Las saca del domicilio de Rizzanelli y las lleva provisoriamente a la casa de los Orsini, sita en la misma localidad, como instancia previa al traslado. Posteriormente da cuenta de su decisión a la policía, al mismo tiempo que radica una denuncia contra Juan, Saturnino y Remigio Rizzanelli por violación y ultraje al pudor. "... a los treinta días del mes de junio de mil novecientos ocho, compareció en esta Comisaría una persona para hacer una denuncia la que al solo objeto de constatar su identidad prestó juramento de Ley en forma por el que prometió decir verdad 
en cuanto exponga. Dijo llamarse Juan Aceto, italiano de cuarenta y un años de edad, soltero, Sacerdote y con domicilio en esta localidad y expuso: Que en su carácter de tutor de las menores $M$. recurre a esta Comisaría porque el veinticuatro del actual retiró de la casa del Sr. Remigio Rizzanelli la menor de diez y seis años Serviliana M. y la de quince años Angela M., depositándola provisoriamente y hasta tanto fueran enviadas a Bahía Blanca en la casa de familia del S. Raúl Orsini. Que desde el dia que las retiró de lo de Rizzanelli y desde el mismo momento fueron depositadas como dice antes en lo de Orsini. Que el día veinte y seis del que sigue, en la tarde Serviliana $M$. le manifestó que durante había permanecido depositada en lo de Rizzanelli habia sido ultrajada en su pudor por el mismo Rizzaneli y como ella se opusiera a su voluntad conseguía aprovecharse de ella castigándola y que como el exponente es el tutor de la menor y sobre él recae toda responsabilidad pide que la autoridad tome intervención para esclarecer los hechos que expone. Que la menor Angela le ha manifestado que Rizzanelli la castigó varias veces intentando deshonrarla. Héchole saber que tiene que justificar o presentar los documentos que acrediten su tutoría sobre esas Menores, lo hizo en este acto, presentándolos..."

La denuncia anterior inició la apertura del sumario, donde constan las deciaraciones de ambas hermanas, las cuales no pudieron firmar por ser analfabetas. El interrogatorio responde a la forma inquisitorial donde la pregunta induce, necesariamente, la respuestas. Serviliana inculpa a los Rizzanelli, sin dar mayores detalles: "... En la casa de Rizzanelli estuvo depositada unos cinco meses. Que en el último mes de junio Rizzanelli empezó por castigarla y darle mala vida llegando por último los hijos de éste Juan y Saturnino a abusar de la declarante pues por la noche se iban a la pieza donde ella y su hermana Angela dormian y una vez alli abusaban tanto con ella como con su hermana durmiendo juntos, que en esa fecha la declarante se encontró algo enferma, ignorando si estaba embarazada. Que Juan Rizzanelli es el que tuvo trato con ella y Saturnino con su hermana Angela.... Que no le dio aviso a Rizzanelli Remigio porque tenía temor de que la castigara... Preguntada cuantas veces ha hecho esa operación, dijo: que una sola vez...". Seguidamente el sumariante pregunta "...si Remigio Rizzanelli para llevar a cabo ese hecho la castigó primeramente y por qué causa, Contestó: que sí y que la castigó porque no quería acceder a tener trato con

7 Archivo Histórico Provincial de Río Negro (en adelante AHPRN), Juzgado Letrado, Exp. Aceto Juan, Presbitero, su denuncia contra Juan, Saturnino y Remigio Rizzanelli, por violación y ultraje al pudor, n. 8942-1908, Leg. 224, folio 1 y $1 \mathrm{v}$.

8 Ibidem, folios 1 v. a 2 v. 
él..." ${ }^{\mu 8}$.

Angela, por su parte, agregaba: "... que Remigio Rizzanelli tuvo trato con ella tres o cuatro veces y que un hijo de éste llamado Saturnino también tuvo trato carnal con ella por repetidas veces y que esta operación la hicieron de tres meses a esta parte, que como ella se negara a esas cosas Remigio Rizzanelli empezó a castigarla hasta que por fin ella por no ser martirizada accedió a esas cosas... que igual cosa resultó con su hermana Serviliana pues Rizzanelli Remigio y el hijo de éste llamado Juan han tenido trato carnal y que ella sabe eso porque dormia en la misma pieza que su hermana, atrancando la puerta por dentro con un palo, pero los Rizzanelli nombrados iban de noche y la desatrancaban acostándose en la misma cama que ellas...".

Las dos declaraciones fueron firmadas solamente por Francisco Muratorio, comisario sumariante. El tres de julio de 1908 la comisaría quedó a cargo del comisario Angel Bordo. Este detiene a los Rizzanelli, quienes en sus declaraciones niegan los hechos. En su defensa, Saturnino afirma que su habitación se encuentra lejana de la de sus primas; Juan dice que no duerme en la casa paterna sino en el negocio de botica que es propiedad del padre; y Remigio declara haberse encontrado ausente durante el tiempo que las menores estuvieron en su casa a cargo de su esposa.

Seguidamente, y con el mismo resultado, el comisario procedió al careo entre las víctimas y los imputados. En el careo entre Remigio y Angela, ésta afirma que su tío llegó hasta "...amenazarlas de darles muerte si no tenían con él contacto carnal y hasta las ha obligado a salir de la habitación para cometer con él actos deshonestos y tan es así que estando apunto de casarse la diciente con su novio Domingo Millapán, se lo impidió porque ya su tío había tenido con ella concúbito y pretendía tenerla como mujer..."

El comisario libera a los acusados por no existir méritos suficientes y traslada el sumario al jefe de policía del territorio, excusándose por no poder establecer la veracidad de los hechos, ya que en Choele Choel no existe "...médico ni partera para practicarse un examen pericial... y en atención a la edad de éstas... sería exponerlas a la pérdida del resto del pudor o delicadeza que les queda... " ${ }^{\prime \prime}$. Cuando la causa pasa a la justicia letrada el fiscal J.

9 Ibidem, folio 8.

10 lbidem, folio $8 \mathrm{v}$. 
S. Aguilar solicita que se prosiga la instrucción ya que "...en autos existen indicios suficientes de culpabilidad en los procesados...". Al mismo tiempo que requiere "...indispensable el examen médico de las menores... pido se las haga acudir a esta Capital... "1". Serviliana y Angela son trasladadas hasta el colegio María Auxiliadora a cargo de Sor Josefina Piccardo.

El Dr. Hedelman, residente en la localidad de Viedma, fue designado para practicar la revisación médico legal y determinar si efectivamente las menores fueron violadas. A partir de ese momento se inicia la segunda instancia de violencia. El médico inspecciona los cuerpos y sanciona las conciencias ${ }^{12}$. Las examina dos veces -ya que ambas se resisten- estando presente la enfermera Clara del Hospital Salesiano, sala de mujeres. En el informe final, luego de la observación y palpación manual de los órganos genitales, el médico describe el estado anatómico y fisiológico de los aparatos reproductores, al mismo tiempo que adelanta detalles del temperamento de las víctimas. Respecto de Serviliana afirma "...parece que se trata de una menor mentirosa, pues negó varios hechos relativos a su estado, edad y menstruación, para corregirse y volver a dar informes falsos si no me impusiese y le declarase que mentia descaradamente. No se dejó examinar y luego de armarme de paciencia pude constatar los hechos"13. A medida que va haciendo la descripción anatómica, el médico sospecha que la infección genital de Serviliana se deba a una posible blenorragia. Agrega, entre otras cosas, que "...el himen eréctil al menor contacto digital indica una naturaleza fogosa... aunque no haya sido histérica o no presente síntomas de histerismo puede haberle faltado el valor de gritar o de defenderse si fue atemorizada..." ". Respecto de Angela, elaboró el siguiente informe, “...tiene edad para comprender, pero es muy ignorante. Es inclinada a mentir y casi no se deja examinar. Es de buena constitución, tiene bastante fuerza... no presenta sintomas de histerismo o alcoholismo... la vulva, himen y vagina, duros y sin relajación indica que hubo raras veces contacto sexual... "15. Hedelman luego de pronunciarse de manera confusa sobre el motivo que determinó su intervención, finaliza el informe diciendo, "...ni Serviliana ni Angela han querido decir cuál fue la primera víctima,

11 Ibidem, folio $9 \mathrm{v}$.

12 Para un análisis de las prácticas médico legales, cf. Jorge Salessi, Médicos, maleantes y maricas, Rosario, Beatriz Viterbo Editora, 1995.

13 Ibidem, folio 12.

14 Ibidem, folio 14.

15 Ibidem folios 15 a $16 \mathrm{v}$. 
pero aseguran que ambas lo fueron en un brevisimo instante [...] Un hombre de regular potencia puede efectuar dos coitos seguidos, con mujeres distintas, aún después de luchar con ellas venciéndolas.... Quizás convenga examinar al inculpado... "16.

Pero, a los inculpados nunca se les exigió revisación médica. El expediente continúa con las declaraciones indagatorias de las menores, donde ratifican lo expuesto en la instancia sumarial. La última noticia sobre el destino final de las jóvenes es una carta que Sor Josefina Piccardo envía al Juez Letrado, Dn. Alfredo Torres, fechada 23 de diciembre de 1908, donde afirma, "...en el mes de Setiembre del corriente año por orden de ese $H$. Juzgado traje de Bahía Blanca a Viedma, las menores Serviliana y Angela Macedo. Desearía saber, donde debo dirigirme para hacerme abonar los gastos de traslación de las mismas, que importan: tren $\$ 4,15$ - Galera $\$ 80,00$, -Posadas $\$ 8,00$. Su total $\$ 92.15 \ldots$ "11.

\section{B}

La historia de Rosa E. tiene alguna similitud con la anterior. En 1889, era una joven de catorce años que había huido del hogar debido a los malos tratos que le daba su padrastro Tristán Paes. Su madre Hipólita, reclama al Juez Letrado la devolución de su hija, inculpando a personas deshonestas por los malos consejos "...mujeres y hombres corrompidos $y$ de corazones mezquinos que no han podido ver tranquila a una pobre criatura, sin inducirla la mal, a fin de que frecuente como ellos, los trinquetes y demás puntos de corrupción a los que jamás ha pisado... vengo ante el Sr. Juez pidiendo que como madre me sea entregada mi hija no para tenerla a mi lado Sr. porque mal aconsejada como está sería para molestar nuevamente la atención de V.S. sino para entregarla a las santas Hermanas de la Caridad de este punto o de Patagones para que algún día sea útil a la sociedad..."18

En las declaraciones de Rosa se explícita el motivo de la fuga del hogar, acusa a su padrastro que "...le daba mal trato y por repetidas veces había intentado hacer uso de ella y corromperla valiéndose unas veces de alhajas $y$ ofertas $y$ otras tratando de violentarla... que su madre era sabedora del mal proceder de su esposo y no la colocaba en otra casa...

16 Ibidem, folios 16 v. y 17

17 Ibidem, folio 19.

18 AHPRN, Justicia Letrada, Exp. 223-1889, Echavarría Hipólita reclamando una hija, folio 1. 
(por eso) tomo la decisión de refugiarse en los de Christiansen..." "19. El Juez Letrado Abraham Arce determina que la menor quede depositada en el Colegio de las Hermanas de la Caridad ya que "...por la declaración de la menor Rosa E. se fugó de la casa de la madre por razones de su propia dignidad... Que aparte de esto, por el art. 308 del Código Civil, la madre viuda que contrae segundas nupcias pierde la patria potestad.... puesto que la lógica es que, como la mujer que contrae matrimonio entra en el dominio del esposo, equiparándose con los menores en ciertos actos jurídicos, sin poder comparecer en juicio, ni administrar bienes, por consiguiente no puede continuar ejercitando tutela cuando ella misma está bajo la dependencia del esposo.... Por lo expuesto y de acuerdo al Art. 308 citado se declara que Da. Hipólita E. ha perdido la patria potestad, por su matrimonio con el Sr. Paez, que no es el padre de la menor... "20. Finalmente Rosa se fuga del colegio y va de casa en casa, unas veces refugiándose por su propia decisión y otras depositada por la justicia. Su madre fallece y finalmente en su último depósito en el Colegio de la Caridad es rechazada por la superiora, quien se presenta ante el Juez ha exponer el caso “...compareció la Señora Superiora de las Hermanas de la Caridad Sor Juana Borgna, dijo: que la menor Rosa E. que acababa de ser colocada en el Colegio por el oficial de Justicia, le había manifestado el deseo de hablar con el Sr. Juez, por cuyo motivo la traía a su presencia.... la menor se expresó del modo siguiente: que no podía estar en la casa de las Hermanas porque sería dar mal ejemplo y un bochorno para el colegio porque se encontraba en mal estado, embarazada, por el Sr. Coronel Don Napoleón Berreute ${ }^{21}$, con el cual ha vivido en concubinato carnal..... que la primera vez que tuvo acto carnal con el Coronel Berreute fue en la Gobernación donde vivía y que fue conducida por su madre, hoy finada, y que después ella sola continuaba yendo todas las noches a la misma casa del coronel...". El caso continúa con la intervención de su tutor, de apellido Bresciano, quien expuso que tenía casa donde depositarla. La menor expresó “...más perdida de lo que estoy no puedo estar y deseara volver a la casa de mi perdición que es la de Dn Angel Benítez... "22, propuesta que fue aceptada por el tutor y por el juez.

19 Ibidem, folio $6 \mathrm{v}$.

20 Ibidem, folio 12.

$21 \mathrm{El}$ coronel Berreute fue gobernador del territorio.

22 Ibidem, folio 24 y $24 \mathrm{v}$. 
Otro caso que nos remite a la pérdida de la patria potestad es el de la india Benjamina y su hija Dorotea, quienes habitaban en Viedma. En 1893, Dorotea tenía doce años, cuando fue expuesta a la intervención de la justicia. Tres años atrás, su madre se había unido de manera ilegítima con el agente de policía Tomás Rodríguez. La situación marital de hecho fue conocida por el Defensor de Incapaces quien elevó una nota al gobernador interino. En ella expresaba "...ha llegado un comunicado a mi defensoría que la mujer indigena Benjamina... mantiene relaciones ilicitas con un agente de policia... tiene una hija menor llamada Dorotea que según los informes recibidos no tardará en seguir una vida licenciosa, pues con frecuencia se la ve de noche en la calle sola y en conferencias con mujeres de mala vida..." "23. El Defensor de Menores la depositó en casa de Lucas Danigno, "...para evitar la fuga o el trasporte de dicha menor..."24. La madre se presenta al juez letrado exponiendo "...se invoca que vivo con un hombre que no es mi esposo, es cierto, pero este punto quedará muy en breve subsanado casándome con él, con quien hago vida matrimonial hace tres años... pido al Sr. Juez quiera desechar como injusta la demanda que me ha entablado colocando a mi hija en casa del Dr. Iribarne Dn Guillermo, o en casa del Comandante Dn. Miguel Vidal o en lo del Sr. Juan Olha, hasta tanto pruebe mi casamiento anunciado y la conducta honesta de toda mi vida..." "2s. Pero Benjamina, de todos modos, perdió a su hija.

\section{D}

Una situación similar soportó otra india llamada Margarita L., de profesión lavandera, quien vivía en General Roca con su hija Dominga de quince años. La menor fue depositada en 1909, en la casa de Miguel Muñoz, por la orden del ex-comisario Domingo Palaciano. Un año después, Dominga se escapa y vuelve al hogar con su madre. Esta escribe al juez letrado, luego de presentarse ante el juez de paz de la localidad, "... me dirijo a Usia... pidiéndole como madre que soy que la haga sacar de la casa del Sr. Muñoz y que venga a mi poder o que sea depositada en otra parte donde puede ser mejor atendida, porque la mu-

23 AHPRN, Justicia Letrada, Exp, 7802-1893, El Defensor de Incapaces contra Dna. Benjamina sobre destitución de la patria potestad que ejerce en su hija menor Dorotea, folio 1.

24 Ibidem.

25 Ibidem, folios 4 y $4 \mathrm{v}$. 
chacha fue depositada por un año y hace dos meses que ha cumplido el año y además que en la casa del Sr. Muñoz la castigan a mi hija, la tienen casi completamente desnuda, como si no tuviera madre. También Sr. Letrado le comunico que yo no puedo ir a ver a mi hija, puesto que no lo permite el Sr. Muñoz..."26

El defensor de menores pidió informes a la policía sobre la vida de Margarita, alegando que obraban en su poder informes desfavorables. El comisario inspector responde “...tratándose Margarita L. de una mujer de las tituladas de Regimiento, de costumbres deshonestas, públicamente conocida y repudiada, omitase la instrucción del sumario para comprobar el hecho..." "27. El juez letrado dictaminó el regreso de Dominga a casa del Sr. Muñoz, tal como lo aconsejara el defensor de menores.

Mientras tanto, su madre india no dejaba de reclamar por su hija. Claro está que por aquellos años ya nadie se acordaba de los ríos de tinta que corrieron denunciando el cautiverio de las jóvenes blancas en toldos de Tierra Adentro, utilizadas como mano de obra. Y por las cuales, los jefes militares y los sacerdotes pagaban en especie y en plata por su rescate, de la barbarie.

\section{E}

En 1910, María H. tenía quince años, estaba depositada en casa del jefe de policía del territorio, por orden del Juez Letrado Abraham Arce. María decidió quitarse la vida ingiriendo formolina, hecho que provocó la apertura de una sumario. Intervino el médico Hedelmann -ya mencionado en un caso anterior- en la revisación médica legal, quien afirmó “...ha habido tentativa de suicidio o simulación..."

Cuando María fue interrogada por la policía expresó: "...habiendo sido reprimida por su patrona en la casa en que se encuentra depositada por una falta que había cometido le dio rabia y se retiró a otra pieza, que se encontraba sola y agarró un frasco el cual

26 AHPRN, Justicia Letrada, Exp. 5733-1906, Margarita Luna sobre reclamo de su hija Dominga, folio 1.

27 Ibidem, folio 6 .

28 AHPRN, Justicia Letrada, Exp. 2019-1910, Hernández María, sobre tentativa de suicidio, folio 4. 
contenía aproximadamente medio dedo de un remedio para matar moscas... que no tuvo el propósito de quitarse la vida, que en la casa siempre se le dio buen trato y que la cuidan como a una hija.... que cuando ocurrió se encontraba su patrón fuera de casa...." ${ }^{29}$. El expediente se archivó y María retornó a la casa del jefe de policía.

$\mathbf{F}$

El suicidio no fue el recurso de otra joven, llamada María A, sino la fuga. En 1892, esta joven tenía diecisiete años y fue depositada en la casa del Sr. Costerg en Carmen de Patagones, de donde se fugó a los siete días, refugiándose con otras mujeres -Mercedes lbáñez de veintisiete años y Carolina Luján de diecisiete- que vivían en casa del cabo de policía Pedro Sotelo. Este, cuando es interrogado dice desconocer el hecho, amparándose en la innumerable cantidad de personas que visitan su domicilio.

También fue interrogada María, y cuando se le preguntó si había frecuentado los bailes públicos, denominados trinquetes, respondió que sólo una vez. El dueño de la casa de bailes Nicolás Ramayan respondió, que la menor había estado presente "...pero que no se lo había solicitado... "30. El comisario de Viedma, por orden del juez letrado depositó la menor en casa del Tte. Coronel Martín W. Gras, quien pide que se instruya sumario a las amigas de María. En virtud del pedido el defensor de menores solicita, "...es necesario para escarmiento del porvenir que dicha Mercedes sufra algo de corrección por ser reincidente de alojar en su casa a la menor $A_{\text {, }}$ con el fin tal vez de aumentar el número de niñas desgraciadas, viviendo con el lucro de la ignominia... llevándolas al camino directo del hospital y la miseria..." ${ }^{31}$.

Asimismo, el fiscal ad hoc solicita la declaración indagatoria de Mercedes Ibáñez y de Carolina Luján, luego de lo cual dictaminó que “...Mercedes Ibáñez es autora de corrupción de menores en la persona de María A.. Carolina Luján, según declaración propia es también menor de edad... huérfana de padre y vive separada de la madre ejerciendo la vi-

29 Ibidem, folio 2.

30 AHPRN, Justicia Letrada, Exp. 116-1892, Mercedes N. y Carolina N. sobre corrupción de la menor María Abel, folio 2.

31 Ibidem, folio 3. 
da airada y escandalosa en los bailes públicos, por tanto este Ministerio es de opinión que a Mercedes Ibáñez se la castigue con los dispuesto en el art. 132 del Código Penal en su parte mínima, y a la menor Carolina Luján que sea depositada también en el colegio de las Her-

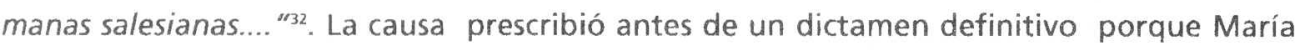
A. cumplió la mayoría de edad. Mientras que a sus amigas les fue dictado el sobreseimiento provisional por el nuevo fiscal Lucas Danigno.

\section{3}

Los seis episodios de la vida de estas jóvenes que hemos relatado -seleccionadas por ser casos representativos- tienen muchos puntos en común. Todas, por una u otra circunstancia, se encontraban a disposición del poder judicial. Sus vínculos familiares habian sido debilitados, ya sean por haber sido arrancadas de sus hogares o porque eran huérfanas. En todos los casos fueron depositadas en los conventos de monjas y en casas de familia, cumpliendo funciones de domésticas. Otras se transformaron en prostitutas impagas, que soportaron el abuso sexual de miembros de su grupo familiar, de los tutores y de los varones que habitan en los domicilios de depósito. Estas situación sólo podía superarse por la mayoría de edad o mediante estrategias de fuga y suicidio -en este último caso posiblemente se tratase de la resignificación de una práctica tradicional de las sociedades indias-. Pero en esta realidad social, la mayoría de edad no implicaba ninguna ventaja: jurídicamente continuaban siendo menores y la salida al mercado laboral coincidía con el debilitamiento de los vínculos parentales y sociales. Así, fue muy común que el disciplinamiento iniciado con el depósito fuera continuado con otros procesos por vagancia e inmoralidad, terminando frecuentemente con el secuestro en la cárcel de mujeres, que en este territorio nacional funcionaba en los conventos de la orden salesiana de María Auxiliadora.

Asimismo, al secuestro del cuerpo se sumó el disciplinamiento de las conciencias y el silenciamiento de la voz. Las declaraciones de las menores fueron requeridas en un contexto coactivo que presumía la culpabilidad antes que la inocencia. Los interrogatorios adoptaban la forma inquisitorial. Asi se fue conformando una imagen de atentado contra la moral pública y de libertinaje que fue una construcción intelectual de los funcionarios y agentes estatales, de los médicos y sacerdotes, y de la prensa local. Dicho en otros términos, es posible comprender, según los nudos argumentativos del discurso, que además del aprove-

32 Ibidem, 19. 
chamiento material que para estos individuos significó el control del mercado de mano de obra juvenil femenina, su universo valorativo jugó un rol importante a la hora de poner en acto las nuevas reglas de juego. Así, nuestras interpretaciones son en parte resultado de la ciencia y de la experiencia de aquellos hombres ${ }^{33}$, dispuestos a corregir lo que consideraban según el sentido común y el buen tino, los males que aquejaban a la sociedad.

En este sentido, hay que tener en cuenta que en la sociedad patagónica postconquista existió una confrontación permanente entre diferentes universos normativos. La conducta moral de la mujer india poco o nada tenía que ver con las disposiciones que obligaban a la unión marital monogámica, cristiana y legalizada. En estas sociedades, las relaciones entre los sexos estaban regidas de una manera diferente: la libertad sexual de las mujeres solteras se regulaba solamente por los límites que imponía la propia voluntad; la fidelidad que debía mantener la mujer casada se vinculaba con la necesidad de conservar la pureza del linaje; y la poligamia era una práctica aceptada, según la riqueza material del varón.

Ahora bien, este universo normativo contrario al modelo de dominación fue condenado por la moral pública dominante y desestructurado por la coacción extraeconómica fundada en derecho. La imposición de la familia monogámica, la nueva definición de género y el control de los brazos juveniles de los grupos domésticos por parte del Estado, aceleró el proceso de proletarización. Así, los destinos individuales de las menores estuvieron delimitados por la profunda transformación que implicó la conformación del Estado Nacional y el desarrollo de las relaciones capitalistas de producción, situación que trajo aparejada la desestructuración de los vínculos familiares, cosanguíneos, simbólicos y de alianza, y las pautas de convivencia tradicionales en la región. La vida cotidiana, la relación entre los sexos y las conductas íntimas pasaron a estar reglamentadas por el Estado y la Iglesia, mediante el uso de la violencia institucional e ideológica que afecto a las conciencias y los cuerpos.

4

El análisis del Estado Nación de base republicana no puede quedar exento del abordaje de las múltiples intermediaciones que existen entre los dos planos que la ideología liberal -que fue su sustento- separó de manera tajante: el espacio público y el espacio priva-

33 Carlo Guizburg, Historia Nocturna, un desciframiento del aquelarre, Barcelona, Muchnik Editores, 1991: 90. 
do. En rigor de verdad ambos planos se entrecruzan, y de manera mucho más estrecha cuando los sujetos implicados no pueden esgrimir prestigio social y ventajas económicas que, a la manera de diques de contención, posibilitan para unos pocos el resguardo de sus conductas íntimas. En esta configuración histórica de poder, la dimensión jurídica nunca opera por fuera de las prácticas sociales, de los usos y del sentido común, encubiertos en marcos ideológicos de múltiples significados. La costumbre, cual sustento del derecho, continúa perviviendo como norma moral deseable.

Las décadas que separan la historia de filomena con las de aquellas niñas que vivieron a principios de siglo en el Territorio Nacional del Río Negro ponen en evidencia un problema olvidado por la historiografía argentina que aborda la construcción de la dimensión estatal de signo republicano: la ingerencia del estado en el destino de los menores. La infancia y la primera juventud son vistos como concernientes al ámbito de la familia. Y las diferentes historias de la vida privada hacen referencia a las imágenes e ideologías que el siglo XIX y XX construyó sobre los párvulos. Así, en la descripción de esa ideología quedan sepultadas e indiferenciadas las condiciones sociales y étnicas de los menores, en tanto sujetos históricos.

\section{Bibliografía}

KOBAYASHI, José María (1985), La educación como conquista, México, El Colegio de México.

AISPURU, Pilar Gonzalbo, (1990) Historia de la educación en la época colonial. El mundo indigena, México, El Colegio de México.

ARGERI María E. y CHÍA Sandra, (1997), "Bajo la lupa del poder. La vida cotidiana en los hogares boliches del Territorio Nacional del Río Negro, Norpatagonia, 1880-1930", en Boletin Americanista, Barcelona.

SALESSI, Jorge, (1995), Médicos, maleantes y maricas, Rosario, Beatriz Viterbo Editora.

GUIZBURG, Carlo (1991), Historia Nocturna, un desciframiento del aquelarre, Barcelona, Muchnik Editores. 